Gynecologic and

Obstetric Investigation
Gynecol Obstet Invest 2011;71:236-239

DOI: $\underline{10.1159 / 000319240}$
Received: March 31, 2010

Accepted after revision: July 12, 2010

Published online: December 16, 2010

\title{
Lidocaine Does Not Reduce Pain Perception during Gel Instillation Sonography or Subsequent Office Hysteroscopy: Results of a Randomized Trial
}

\author{
T. Van den Bosch ${ }^{a} \quad$ D. Van Schoubroeck ${ }^{a} \quad$ A. Daemen ${ }^{b} \quad$ E. Domali ${ }^{a}$ \\ $\begin{array}{lll}\text { V. Vandenbroucke } & \text { B. De Moor } & \text { J. Deprest } \\ & \text { a } & \text { D. Timmerman } \\ & \text { a }\end{array}$ \\ ${ }^{a}$ Department of Obstetrics and Gynaecology, University Hospitals Leuven, and ${ }^{\mathrm{b}}$ Department of Electrical \\ Engineering, ESAT-SCD, K.U. Leuven, Leuven, Belgium
}

\section{Key Words}

Gel instillation sonohysterography · Ultrasound - Pain •

Lidocaine $\cdot$ Hysteroscopy

\begin{abstract}
Background: To evaluate if the addition of lidocaine to the gel used for gel infusion sonohysterography (GIS) reduces pain experienced during GIS or subsequent hysteroscopy. Methods: A total of 142 consecutive patients were randomized using computer-generated random integers. In 79 patients, GIS was performed with a gel containing lidocaine (Instillage ${ }^{\circledR}$ ) and in 63 patients the gel did not contain lidocaine (Endosgel $\left.{ }^{\circledR}\right)$. Immediately after GIS, 132 patients (94\%) underwent office hysteroscopy. The women were asked to fill in a questionnaire including a $100-\mathrm{mm}$ visual analogue scale (VAS) score after each examination. Results: The mean age (SD) was 50.8 (12.1) years; $58.5 \%$ were premenopausal and $15.6 \%$ were nulliparous. The median (interquartile range (IR)) VAS score during GIS for all women was 6 (19.5): 8 (21) for the lidocaine group versus 5 (18.2) for those who received gel without lidocaine. The median (IR) VAS scores during hysteroscopy in the total group, the Instillagel group and the Endosgel group were 15.5 (43.2), 24 (35) and 9 (52), respectively. None of the differences were statistically significant.
\end{abstract}

Conclusion: The addition of lidocaine to the gel used either for GIS or prior to office hysteroscopy does not reduce the procedure-related pain.

Copyright $\odot 2010$ S. Karger AG, Basel

\section{Introduction}

Several diagnostic modalities are currently used to explore abnormal uterine bleeding, including transvaginal ultrasound with or without contrast infusion, (office) hysteroscopy and endometrial sampling. Although those techniques are well accepted, patients may still experience moderate to severe pain during some of the procedures [1]. Recently the instillation of gel instead of saline has been proposed for sonohysterography [2]. In an earlier prospective observational cohort study, we observed that the procedure-related pain during contrast sonohysterography, as well as during subsequent hysteroscopy and endometrial sampling was less in the gel infusion sonohysterography (GIS) group as compared to the saline contrast sonohysterography group [3].

The aim of the present randomized study was to evaluate if the addition of lidocaine to the gel used for GIS would further reduce the pain as experienced during GIS.

T. Van den Bosch, MD, PhD

Department of Obstetrics and Gynaecology, University Hospitals Leuven

Herestraat 49, BE-3000 Leuven (Belgium)

Tel. +32 1634 3642, Fax +32 16344205

E-Mail thierry.van.den.bosch@skynet.be 
Table 1. Patients' characteristics

\begin{tabular}{|c|c|c|c|c|}
\hline & $\begin{array}{l}\text { GIS } \\
\text { group }\end{array}$ & $\begin{array}{l}\text { Hysteroscopy } \\
\text { group }\end{array}$ & $\begin{array}{l}\text { Gel with } \\
\text { lidocaine }\end{array}$ & $\begin{array}{l}\text { Gel without } \\
\text { lidocaine }\end{array}$ \\
\hline Number & 142 & 132 & 79 & 63 \\
\hline \multicolumn{5}{|l|}{ Age, years } \\
\hline Mean $\pm \mathrm{SD}$ & $50.8 \pm 12.1$ & $50.6 \pm 12.4$ & $49.4 \pm 11.4$ & $52.5 \pm 12.8$ \\
\hline \multicolumn{5}{|l|}{ Menopausal status } \\
\hline Postmenopausal & $55(38.7 \%)$ & $51(38.6 \%)$ & $25(31.6 \%)$ & $30(47.6 \%)$ \\
\hline Premenopausal & $83(58.5 \%)$ & $78(59.1 \%)$ & $52(65.8 \%)$ & $31(49.2 \%)$ \\
\hline Perimenopausal & $4(2.8 \%)$ & $3(2.3 \%)$ & $2(0.3 \%)$ & $2(3.2 \%)$ \\
\hline \multicolumn{5}{|l|}{ Parity } \\
\hline Nullipara & $22(15.6 \%)$ & $21(15.9 \%)$ & $12(15.4 \%)$ & $10(15.9 \%)$ \\
\hline \multicolumn{5}{|c|}{ Endometrial thickness on ultrasound, $\mathrm{mm}$} \\
\hline Median & 7.9 & 7.5 & 7.9 & 7.7 \\
\hline IR & $5.1-11.9$ & $4.9-11.9$ & $5.5-11.6$ & $4.5-12$ \\
\hline
\end{tabular}

$\mathrm{SD}=$ Standard deviation; IR = interquartile range. 'Postmenopausal' status was defined as more than 12 months' amenorrhea in non-pregnant women over age 40; 4 women in whom the menstrual history was equivocal were categorized as 'perimenopausal'.

Secondly, we evaluated if the addition of lidocaine to gel instillated prior to office hysteroscopy reduces the procedure-related pain. The effect of gel with and without lidocaine was compared.

\section{Materials and Methods}

This study was a randomized clinical trial conducted between December 2006 and October 2007 at the Department of Gynaecology of the University Hospitals Leuven, Belgium. The study was approved by the hospital's Medical Ethics Committee, and written informed consent was provided by all patients.

A total of 142 consecutive patients presenting at the department's One-Stop Bleeding Clinic were randomized into one of the two groups using numbers generated randomly by a computer [http://www.random.org/intergers/]. The numbers were picked independently of each other and may therefore contain duplicates. Because the randomness comes from atmospheric noise, meaning that the numbers are picked independently of each other like rolls of a die, the distribution is not necessarily 50/50. The allocations were placed in opaque-sealed numbered envelopes. The ultrasound was performed using a GE Voluson E8 ultrasound machine with a 3D transvaginal probe. Gels with and without lidocaine were used. Both gels are commercially available and have an identical content (sodium lactate, chlorhexidine digluconate, methyl $p$-hydroxybenzoate and propyl $p$-hydroxybenzoate) besides that Endosgel ${ }^{\circledR}$ (Farco-Pharma GmbH, Cologne, Germany) does not contain lidocaine, while Instillage ${ }^{\circledR}$ (Farco-Pharma $\mathrm{GmbH}$ ) does contain $2 \%$ lidocaine. The gel was warmed to $37^{\circ} \mathrm{C}$ to increase viscosity and to facilitate the instillation and was infused through a $2.0-\mathrm{mm}$ neonatal suction catheter. All GIS were performed by the same examiner (T.V.). GIS failed in 3 patients due to cervical stenosis. Within 30 min after GIS, 132 patients (94\%) underwent office hysteroscopy according to the department's bleeding clinic's protocol. Hysteroscopy was performed without local anesthesia using a 3-mm rigid Storz ${ }^{\circledR}$ hysteroscope with a single inflow channel: a speculum was inserted and the cervix was cleaned with a water solution of cetrimonium bromide $0.5 \%$ and chlorhexidine $0.05 \%$. The hysteroscopy was performed mostly without the use of a tenaculum and without dilatation of the cervix. Distention of the cavity was achieved by normal saline and the pressure for distending the cavity was supplied by a pressure cuff pumped up to 0.1 bar. The speculum was removed once the scope had been inserted through the cervical canal.

The patients as well as the medical staff performing the hysteroscopy were unaware which gel had been used. The examiner performing the GIS however was aware of the random allocation. The women were asked to fill in a questionnaire including a 100$\mathrm{mm}$ visual analogue scale (VAS) score about their pain perception during the different procedures: 0 indicating the procedure was not painful at all, and 100 indicating it was the most painful experience one could imagine. The patients had time to fill it in after the ultrasound/GIS procedure and after the hysteroscopy. They completed the questionnaire without the help of any staff member, and were asked to return it at the desk before leaving the clinic.

Statistical analysis used the Mann-Whitney U test to determine the statistical significance of differences in the continuous non-parametric variables between two groups, namely age, endometrial thickness and VAS score. The $\chi^{2}$ or Fisher's exact test were 
Table 2. Final diagnosis

\begin{tabular}{|c|c|c|c|c|c|c|}
\hline Final diagnosis & $\begin{array}{l}\text { GIS } \\
\text { group }\end{array}$ & $\begin{array}{l}\text { Hysteroscopy } \\
\text { group }\end{array}$ & $\begin{array}{l}\mathrm{p} \\
\text { value }\end{array}$ & $\begin{array}{l}\text { Gel with } \\
\text { lidocaine }\end{array}$ & $\begin{array}{l}\text { Gel without } \\
\text { lidocaine }\end{array}$ & $\begin{array}{l}\mathrm{p} \\
\text { value }\end{array}$ \\
\hline Normal findings ${ }^{1}$ & 85 & 80 & & 45 & 40 & \\
\hline Endometrial hyperplasia without atypia & 4 & 4 & & 2 & 2 & \\
\hline Endometrial polyp & 36 & 35 & & 20 & 16 & \\
\hline Intracavity myoma & 12 & 10 & & 10 & 2 & \\
\hline Endometrial malignancy & 5 & 3 & & 2 & 3 & \\
\hline Total & 142 & 132 & 0.98 & 79 & 63 & 0.32 \\
\hline \multicolumn{7}{|c|}{$\begin{array}{l}{ }^{1} \text { Including endometrial atrophy, proliferative- and secretory changes. The 'final diagnosis' has been based } \\
\text { on ultrasound findings }(n=7) \text {, hysteroscopy findings }(n=14) \text {, histological examination after endometrial sam- } \\
\text { pling }(n=63) \text {, histological examination after resection of a lesion at operative hysteroscopy }(n=42) \text { or the } \\
\text { pathological examination of the hysterectomy specimen }(n=16) \text {. }\end{array}$} \\
\hline
\end{tabular}

Table 3. Pain scores during GIS and office hysteroscopy

\begin{tabular}{lllll}
\hline & $\begin{array}{l}\text { Gel with } \\
\text { lidocaine } \\
(\mathrm{n}=79)\end{array}$ & $\begin{array}{l}\text { Gel without } \\
\text { lidocaine } \\
(\mathrm{n}=63)\end{array}$ & $\begin{array}{l}\text { Total } \\
(\mathrm{n}=142)\end{array}$ & $\begin{array}{l}\mathrm{p} \\
\text { value }\end{array}$ \\
\hline $\begin{array}{l}\text { VAS-GIS } \\
\text { Responders }\end{array}$ & 59 & 40 & 99 & 0.5423 \\
$\quad \begin{array}{l}\text { Median } \\
\text { IR }\end{array}$ & 8 & 5 & 6 & \\
$\begin{array}{l}\text { VAS Hysc } \\
\text { Responders }\end{array}$ & $2-23$ & $1-19.2$ & $1.5-21$ & \\
$\quad$ Median & 57 & 37 & 94 & 0.7486 \\
IR & 24 & 9 & 15.5 & \\
\hline
\end{tabular}

VAS = Visual analogue scale $(\mathrm{mm})$; GIS = gel infusion sonohysterography; Hysc = office hysteroscopy; IR = interquartile range; Responders $=$ number of patients who responded to the questionnaire.

appropriately used to determine the statistical significance of differences in the categorical variables menopausal status, parity and final diagnosis. Statistical analysis was performed using SAS Version 9.1 for Windows ${ }^{\circledR}$. Two-sided p values are reported. A probability level of 0.05 was chosen for statistical significance.

\section{Results}

Of the 142 randomized patients, 79 were allocated to gel with lidocaine (Instillagel), whereas 63 patients received a gel without lidocaine (Endosgel). The mean age (SD) was 50.8 (12.1) years; $58.5 \%$ were premenopausal and $15.6 \%$ were nulliparous (table 1 ). The results of the final diagnosis are given in table 2. Altogehther 99 patients $(70 \%)$ returned the questionnaire including the VAS score.

The median (interquartile range (IR) VAS) score during GIS was 6 (19.5) for the total group; 8 (21) for the lidocaine group versus 5 (18.2) for those who received gel without lidocaine. The median (IR) VAS scores during hysteroscopy in the total group, the Instillagel group and the Endosgel group were 15.5 (43.2), 24 (35) and 9 (52), respectively (table 3 ). None of the differences were statistically significant.

No major adverse effects were observed during the study, and all patients were able to leave the clinic within $1 \mathrm{~h}$ after the last examination.

\section{Discussion}

In the present randomized trial we showed that the addition of lidocaine to the gel - used either for GIS or prior to office hysteroscopy - does not reduce procedurerelated pain. In a previous study we reported lower pain scores during contrast sonography of the uterine cavity as well as during subsequent hysteroscopy and endometrium biopsy when gel was used instead of saline for contrast sonohysterography [3]. Gel may facilitate transcervical instrumentation due to its lubrification qualities, causing less discomfort for the patient. Although procedure-related pain is considered tolerable during saline contrast sonohysterography or hysteroscopy [4], some patients might benefit from some pain relief. Different stud- 
ies showed that anesthesia of the cervix, either by paracervical block [5] (randomized open label trial, using 1\% mepivacaine) or using topical lidocaine gel [6] (randomized double-blind, placebo-controlled) does not reduce the pain experienced during hysteroscopy or endometrial sampling. Studies on the use of topical anesthesia into the uterine cavity give conflicting results. Two relatively small randomized double-blind studies using mepivacaine injected through the cervix prior to hysteroscopy or endometrial sampling found a beneficial effect $[7,8]$. Using lidocaine $2 \%$ prior to endometrial biopsy, Hui et al. [9] also reported lower pain scores in the treated group, whereas both Lau et al. [10] (90 patients) and Wong et al. [6] (500 women) did not find any improvement in the pain experienced during hysteroscopy or endometrial sampling after lidocaine instillation (all three studies [6, $9,10]$ were randomized and double-blind). The only randomized study using intrauterine lidocaine $2 \%$ gel [11] prior to Vabra endometrial sampling in 308 patients did not show any pain reduction in the lidocaine group.

The limitation of the study is the dropout rate of $30 \%$, caused by the number of patients who failed to return the questionnaire. This may preclude definitive conclusions. However, since the comparison between gel with and without lidocaine was performed for each procedure separately, and since, at randomization, the numbers generated randomly by a computer were picked independently of each other, our data are still relevant. However, our conclusions should be confirmed in a larger series.

In conclusion, the present randomized trial demonstrates no beneficial effect on patients' pain perception when adding lidocaine to the gel used for GIS or applied prior to other transcervical procedures. However, definitive conclusions should be confirmed by a larger series.

\section{References}

$>1$ Van den Bosch T, Verguts J, Daemen A, Gevaert $\mathrm{O}$, Domali $\mathrm{E}$, Claerhout $\mathrm{F}$, Vandenbroucke V, De Moor B, Deprest J, Timmerman D:Pain experienced during transvaginal ultrasound, saline contrast sonohysterography, hysteroscopy and office sampling: a comparative study. Ultrasound Obstet Gynecol 2008;31:346-351.

-2 Exalto N, Stappers C, van Raamsdonk LA, Emanuel MH: Gel instillation sonohysterography: first experience with a new technique. Fertil Steril 2007:87:152-155.

-3 Van den Bosch T, Betsas G, Van Schoubroeck D, Daemen A, Vandenbroucke V, Cornelis A, De Moor B, Deprest J, Timmerman D: Gel infusion sonography in the evaluation of the uterine cavity. Ultrasound Obstet Gynecol 2009;34:711-714.
4 Leone FP, Carsana L, Lanzani C, Vago G, Ferrazzi E: Sonohysterographic endometrial sampling and hysteroscopic endometrial biopsy: a comparative study. Ultrasound $\mathrm{Ob}$ stet Gynecol 2007;29:443-448.

5 Vercellini P, Colombo A, Mauro F, Oldani S, Bramante T, Crosignani PG: Paracervical anesthesia for outpatient hysteroscopy. Fertil Steril 1994;62:1083-1085.

6 Wong YK, Wong KS, Tang LCH: Stepwise pain score analysis of the effect of local lignocaine on outpatient hysteroscopy: a randomized, double-blind, placebo-controlled trial. Fertil Steril 2000;73:1234-1237.

7 Cicinelli E, Didonna T, Ambrosi G, Schönauer LM, Fiore G, Matteo MG: Topical anaesthesia for diagnostic hysteroscopy and endometrial biopsy in postmenopausal women: a randomized placebo-controlled doubleblind study. Br J Obstet Gynaecol 1997;104: 316-319.

8 Zupi E, Luciano AA, Valli E, Marconi D, Maneschi F, Romanini C: The use of topical anesthesia in diagnostic hysteroscopy and endometrial biopsy. Fertil Steril 1995;63: 414-416. $\checkmark 9$ Hui SK, Lee L, Ong C, Yu V, Ho LC: Intrauterine lignocaine as an anaesthetic during endometrial sampling: a randomized double-blind controlled trial. BJOG 2006;113: 53-57.

10 Lau WC, Tam WH, Lo WK, Yuen PM: A randomised double-blind placebo-controlled trial of transcervical intrauterine local anaesthesia in outpatient hysteroscopy. BJOG 2000;107:610-613.

11 Kozman E, Collins P, Howard A, Akanmu T, Gibbs A, Frazer M: The effect of an intrauterine application of two percent lignocaine gel on pain perception during Vabra endometrial sampling: a randomised double-blind, placebo-controlled trial. BJOG 2001;108:8790. 